\title{
Ecological relevance of strigolactones in nutrient uptake and other abiotic stresses, and in plant-microbe interactions below-ground
}

\author{
Beatriz Andreo-Jimenez • Carolien Ruyter-Spira • \\ Harro J. Bouwmeester • Juan A. Lopez-Raez
}

Received: 12 January 2015 / Accepted: 1 June 2015 / Published online: 10 June 2015

(C) Springer International Publishing Switzerland 2015

\begin{abstract}
Background Plants are exposed to ever changing and often unfavourable environmental conditions, which cause both abiotic and biotic stresses. They have evolved sophisticated mechanisms to flexibly adapt themselves to these stress conditions. To achieve such adaptation, they need to control and coordinate physiological, developmental and defence responses. These responses are regulated through a complex network of interconnected signalling pathways, in which plant hormones play a key role. Strigolactones (SLs) are multifunctional molecules recently classified as a new class of phytohormones, playing a key role as modulators of the coordinated plant development in response to nutrient deficient conditions, especially phosphorus
\end{abstract}

Responsible Editor: Philippe Hinsinger .

B. Andreo-Jimenez $\cdot$ C. Ruyter-Spira $\cdot$ H. J. Bouwmeester Laboratory of Plant Physiology, Wageningen University, Droevendaalsesteeg 1, 6708 PB Wageningen,

The Netherlands

C. Ruyter-Spira

Business Unit Bioscience, Plant Research International, Droevendaalsesteeg 1, 6708 PB Wageningen,

The Netherlands

H. J. Bouwmeester

Centre for Biosystems Genomics, PO Box 98, 6700

AB Wageningen, The Netherlands

J. A. Lopez-Raez $(\bowtie)$

Department of Soil Microbiology and Symbiotic Systems, Estación Experimental del Zaidín (CSIC), Granada, Spain e-mail: juan.lopezraez@eez.csic.es shortage. Belowground, besides regulating root architecture, they also act as molecular cues that help plants to communicate with their environment.

Scope This review discusses current knowledge on the different roles of SLs below-ground, paying special attention to their involvement in phosphorus uptake by the plant by regulating root architecture and the establishment of mutualistic symbiosis with arbuscular mycorrhizal fungi. Their involvement in plant responses to other abiotic stresses such as drought and salinity, as well as in other plant-(micro)organisms interactions such as nodulation and root parasitic plants are also highlighted. Finally, the agronomical implications of SLs below-ground and their potential use in sustainable agriculture are addressed.

Conclusions Experimental evidence illustrates the biological and ecological importance of SLs in the rhizosphere. Their multifunctional nature opens up a wide range of possibilities for potential applications in agriculture. However, a more in-depth understanding on the SL functioning/signalling mechanisms is required to allow us to exploit their full potential.

Keywords Abiotic stress · Arbuscular mycorrhizal fungi · Phosphorus acquisition · Root architecture · Rhizosphere $\cdot$ Root parasitic plants $\cdot$ Strigolactones

\section{Introduction}

The most important assignment of modern agriculture is to provide global food security in a sustainable manner. 
Fifty years ago, the challenge to feed the growing world population was solved by the development of new high-yielding crop varieties and high-intensity agricultural management (Gianinazzi et al. 2010). However, optimal production of these improved varieties/strategies could not be achieved with the natural reserves of nutrients available in most soils. Thus, chemical fertilizers containing nitrogen, phosphorus and potassium (NPK) became an indispensable source of the nutrients required for proper crop growth and food production. However, the cheap source of one of these nutrients, rock phosphate, will be exhausted in a few decades (Cordell et al. 2009). Therefore, there is a need to develop new agronomical strategies to optimize phosphorus $(\mathrm{P})$ usage. Plants can only assimilate $\mathrm{P}$ in its inorganic mineral phosphate form, which is usually present in only low concentrations and is rather immobile in the soil, which results in $\mathrm{P}$ deficiency (Péret et al. 2011; Schachtman et al. 1998). To cope with $P$ deficiency, plants have evolved a wide array of adaptive responses in plant growth, development, metabolism and interaction with soil microorganisms (Péret et al. 2011; Rouached et al. 2010; Smith and Read 2008).

Strigolactones (SLs) are multifunctional molecules classified as a new class of phytohormones that controls several different processes in plants. They play a pivotal role as modulators of the coordinated development of roots and shoots in response to nutrient deficient conditions, especially phosphorus shortage. Accordingly, SLs regulate above- and belowground plant architecture, adventitious root formation, secondary growth, reproductive development and leaf senescence (Agusti et al. 2011; Gomez-Roldan et al. 2008; Kapulnik et al. 2011a; Kohlen et al. 2012; Rasmussen et al. 2012; Ruyter-Spira et al. 2011; Umehara et al. 2008; Yamada et al. 2014). However, novel roles for SLs are emerging, for example, recently they were also shown to play a role in defence responses (Torres-Vera et al. 2014). Despite their importance as plant hormones, they were initially identified as signalling molecules in the rhizosphere. Here, SLs act as host detection cues for root parasitic plants of the Orobanchaceae and symbiotic arbuscular mycorrhizal (AM) fungi from the phylum Glomeromycota (Fig. 1) (Akiyama et al. 2005; Bouwmeester et al. 2007; López-Ráez et al. 2011b). More recently, a role for SLs in another important plant-symbiotic microorganism interaction in the rhizosphere, nodulation, was described (Fig. 1) (Foo and Davies 2011; Soto et al. 2010).

SL biosynthesis and signalling

SLs are mainly produced in the roots and secreted into the rhizosphere, but biosynthesis also has been suggested to occur throughout the plant, although at low or even undetectable levels (Dun et al. 2009; Xie et al. 2010). They are produced at extremely low levels, being active at pico- and nanomolar concentrations, and are unstable in the soil, which hampers their isolation and characterization (Xie et al. 2010). To date 19 different SLs have been characterized, but it has been estimated that the total number of natural SLs might be over 1000 (Akiyama et al. 2010; Ćavar et al. 2014; Zwanenburg and Pospíśil 2013). They have been detected in a wide range of monocotyledonous and dicotyledonous plant species, and each plant is producing a blend of different SLs depending on the species (Ruyter-Spira et al. 2013; Xie et al. 2010). All natural SLs isolated and characterized so far have a similar chemical structure, with a structural core consisting of a tricyclic lactone (the ABC-rings) connected via an enol ether bridge to a butyrolactone group (the D-ring) (Fig. 1) (Ćavar et al. 2014; Xie et al. 2010). The bridge between the C-and D-rings can be rapidly cleaved in aqueous and/or alkaline environments, resulting in their short-lived character, which supports their role as signalling molecules (Akiyama et al. 2010; Xie et al. 2010; Zwanenburg and Pospíśil 2013). SLs have recently been classified into two groups of diastereoisomers, the strigol-type and the orobanchol-type, depending on their C-ring orientation (Fig. 1) (Xie et al. 2013; Zwanenburg and Pospíšil 2013). The AB-rings are less conserved than the CD-rings and can be decorated or modified by for example methylation, hydroxylation, acetylation, etc., giving rise to the different SLs known today (Akiyama et al. 2010; Zwanenburg and Pospíšil 2013). The stereochemistry and structural features of the different SLs are important for their biological activity. For example, the CD part is essential for the parasitic weed seed germination inducing activity, but modifications in the A-ring have little effect on this activity (Akiyama et al. 2010; Xie et al. 2010; Zwanenburg and Pospíšil 2013). For their hyphal branching inducing activity in AM fungi the D-ring is also essential, but the bridge between the CD-rings 
Fig. 1 Chemical structures of strigolactones and roles they play belowground. Strigolactones (SLs) are multifunctional molecules playing several different roles in plants. As plant hormones, they modulate root system architecture. In the rhizosphere, they favour the establishment of beneficial associations with arbuscular mycorrhizal fungi (AM fungi) and rhizobia. SLs also promote the germination of root parasitic plants, allowing a parasitic interaction. Novel rhizosphere roles for SLs may emerge as indicated by?

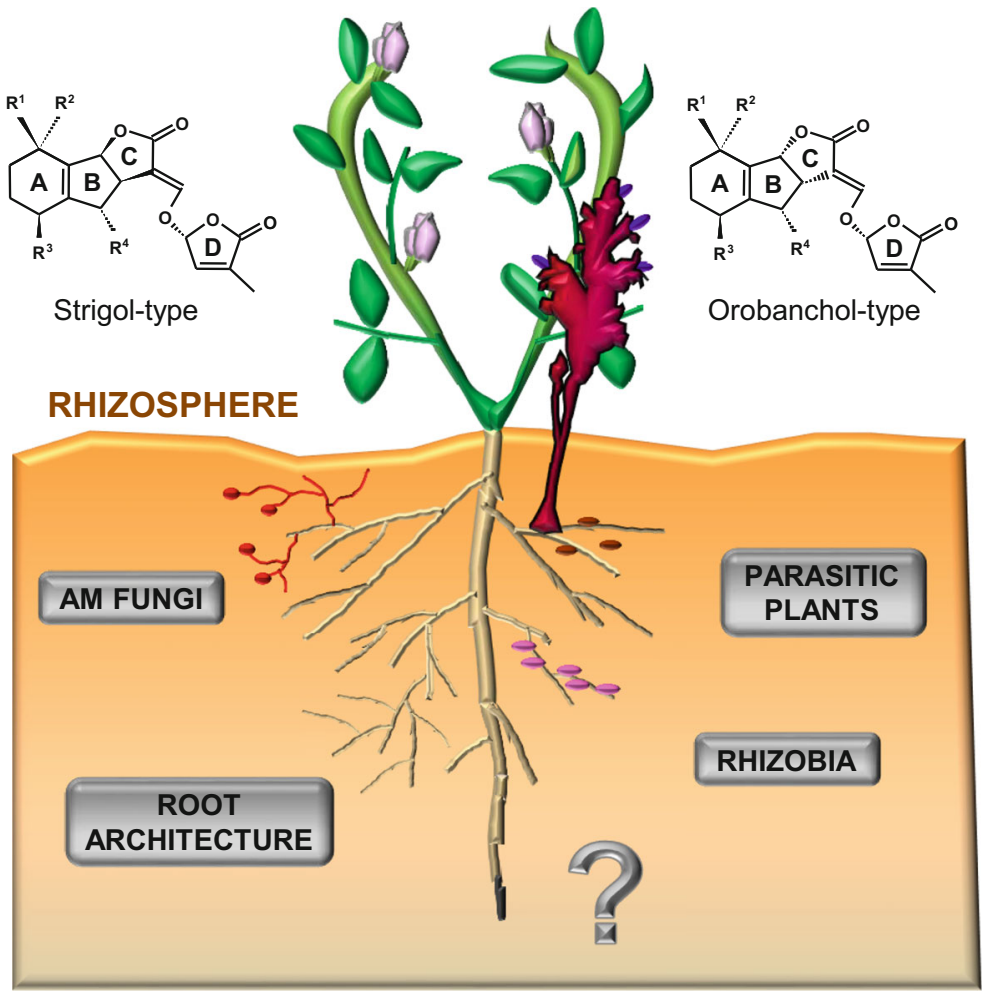

does not necessarily have to be an enol ether (Akiyama et al. 2010; Zwanenburg and Pospíšil 2013). Akiyama and co-workers also showed that the hyphal branching activity depended on the modifications on the AB-ring (Akiyama et al. 2010; Zwanenburg and Pospíšil 2013). The presence of the D-ring is also necessary for hormonal activity of SLs (Boyer et al. 2012). In addition, Boyer and coworkers showed that lipophilicity is an important factor for this activity, with the SLs having a hydrox$\mathrm{yl}$ group on the AB-rings being more active (Boyer et al. 2012).

SLs biosynthetically derive from the carotenoids (López-Ráez et al. 2008a; Matusova et al. 2005) through the conversion of all-trans- $\beta$-carotene to 9-cis- $\beta$-carotene mediated by a $\beta$-carotene isomerase (D27) (Alder et al. 2012). 9-Cis- $\beta$-carotene is transformed into carlactone by sequential oxidative cleavage by two carotenoid cleavage dioxygenases (CCD7 and CCD8) (Alder et al. 2012), and thus SLs belong to the apocarotenoids, as the phytohormone abscisic acid (ABA) (Ohmiya 2009; Walter and Strack 2011). In rice, carlactone is then converted into the strigolactone ent-2'- epi-5-deoxystrigol by a cytochrome $\mathrm{P} 450$, Os900, that is homologous to Arabidopsis MAX1 (Zhang et al. 2014). Another rice MAX1 homolog, Os1400, then converts ent-2'-epi-5-deoxystrigol into orobanchol (Zhang et al. 2014). Rice has five MAX1 orthologs, of which four Os900, Os1400, Os5100 and Os1900 - were shown to rescue the Arabidopsis max 1 mutant phenotype (Challis et al. 2013; Cardoso et al. 2014). Although upon expression in Nicotiana benthamiana Os5100 and Os1900 catalysed the conversion of carlactone into ent-2'-epi-5deoxystrigol (and minute amounts of 5-deoxystrigol), this occurred with very low efficiency, just as for Arabidopsis MAX1 (Zhang et al. 2014). The application of labelled carlactone to Arabidopsis resulted in the formation of a product called SL-LIKE1 and not ent2'-epi-5-deoxystrigol (Seto et al. 2014), although the level of the latter compound may have been beyond the detection level. SL-LIKE1 was recently identified as methyl carlactonate and showed that it is biologically active in inhibiting shoot branching in Arabidopsis (Abe et al. 2014). Therefore, it seems that in Arabidopsis the thus far reported canonical strigolactones (Goldwasser et al. 2008; Kohlen et al. 2011) are minor side products 
or artefacts. That could imply that MAX1 and the rice MAX1 orthologs Os5100 and Os1900 have a different enzymatic activity than rice MAX1 orthologs Os900 and Os1400. Interestingly, although Os1400 is absent in the rice cultivar Bala, this line still produces orobanchol. Therefore, there must be an as yet unidentified cytochrome $\mathrm{P} 450$ present in the rice genome that has a similar activity as this MAX1 orthologue (Zhang et al. 2014; Cardoso et al. 2014). Since Arabidopsis MAX1 also lacks the capacity to convert ent-2'-epi-5deoxystrigol to orobanchol, the minute amounts of orobanchol observed in Arabidopsis root exudates are also likely to result from a similar mechanism (Zhang et al. 2014).

SL perception and signalling require an F-box leucinerich repeat protein (MAX2) and an $\alpha / \beta$-hydrolase (D14) (Gomez-Roldan et al. 2008; Hamiaux et al. 2012; Umehara et al. 2008). Binding of SLs by D14 enables their interaction with MAX2 and this complex facilitates the degradation of the target protein D53 and the transcriptional effector BES1 via the ubiquitin-proteasome system (Jiang et al. 2013; Wang et al. 2013; Zhou et al. 2013), a similar mechanism as for gibberellin perception and signalling. D53 is a class I Clp ATPase protein which acts a repressor of SL signalling, and its degradation prevents axillary-bud outgrowth in rice (Jiang et al. 2013; Zhou et al. 2013). Interestingly, it has been suggested that SLs promote proteasome-mediated degradation of D14 in Arabidopsis, thus limiting their own signalling by a negative feedback loop (Chevalier et al. 2014).

In the present work, we review the current knowledge on the different roles of SLs in the rhizosphere, paying special attention to their involvement in phosphorus uptake by the plant. We focus on their ability to regulate root system architecture and to favour symbiosis establishment with beneficial microorganisms such as AM fungi and rhizobia. Finally, because of their multifunctional character, the potential use of SLs to develop new more sustainable agricultural strategies will be discussed.

\section{SLs and root system architecture}

One of the functions of SLs below-ground is to regulate root development in response to phosphorus shortage (De Cuyper et al. 2015; Kapulnik et al. 2011a; Koltai 2011; Ruyter-Spira et al. 2011). Interestingly, SL biosynthesis is promoted by P-limiting conditions (Table 1)
(Foo et al. 2013b; López-Ráez et al. 2008a; Yoneyama et al. 2007, 2012), and it has been suggested that they play a pivotal role as modulators of the coordinated development of roots and shoots under these unfavourable conditions. On the one hand, increased SL production suppresses the outgrowth of axillary branches/tillers (Kohlen et al. 2011; Umehara et al. 2010), while at the same time they affect various aspects of root growth all aimed to improve phosphate foraging (Mayzlish-Gati et al. 2012; Ruyter-Spira et al. 2011; Sun et al. 2014).

Changes in root development during $\mathrm{P}$ starvation have been most intensively studied in Arabidopsis. Here, it was shown to stimulate lateral root and root hair formation, as well as their subsequent development, and to inhibit primary root growth (Fig. 2) (reviewed by Niu et al. 2013). In maize and rice, $P$ starvation inhibits lateral root formation, while it promotes primary root growth (Li et al. 2012; Sun et al. 2014). Different responses to low $\mathrm{P}$ between these plant species might be due to the fact that Arabidopsis is a non-mycorrhizal plant. However, we should be careful with generalizing root architectural changes when only studying one specific ecotype or variety for each species. For instance, various Arabidopsis ecotypes displayed a different root architectural response to low $\mathrm{P}$ conditions, suggesting that there is natural variation for this response and that it is genetically determined (Chevalier et al. 2003). In Arabidopsis, in the presence of sufficient P, SLs have a suppressive effect on lateral root formation (Fig. 2). Accordingly, SL-deficient mutants have a higher lateral root density (Kapulnik et al. 2011a). They also have a shorter primary root, not only in Arabidopsis, but also in rice and maize (Arite et al. 2012; Guan et al. 2012; Ruyter-Spira et al. 2011). These phenotypes could only be rescued by the application of the synthetic SL analogue GR24 to the SL biosynthesis mutants, but not in those affected in signalling, indicating that SLs regulate root architecture in a MAX2-dependent manner (Kapulnik et al. 2011a; Koltai et al. 2010; MayzlishGati et al. 2012; Ruyter-Spira et al. 2011). Kapulnik and co-workers also showed that the application of GR24 (1 and $3 \mu \mathrm{M}$ ) to Arabidopsis seedlings led to a MAX2dependent increase in root hair length (Fig. 2) (Kapulnik et al. 2011a, b).

The effect of SLs on the regulation of root system architecture (RSA) was shown to depend on the plant's P status (Kapulnik et al. 2011b; Ruyter-Spira et al. 2011). In contrast to the observed response in the presence of 
Table 1 Effect of different abiotic stresses on SL production and/or SL biosynthetic gene expression and AMF colonisation in different plant species

\begin{tabular}{|c|c|c|c|c|c|}
\hline Stress & Plant & Effect on SLs & Effect on AMF colonisation & AM fungus & Reference \\
\hline$-\mathrm{P}$ & M. truncatula & + & + & R. irregularis & Bonneau et al. 2013 \\
\hline$-\mathrm{P}$ & M. truncatula & + & ND & ND & Yoneyama et al. 2012 \\
\hline$-\mathrm{P}$ & P. sativum & + & + & R. irregularis & Foo et al. 2013a, b \\
\hline$-\mathrm{P}$ & O. sativa & + & ND & ND & Jamil et al. 2011a, b \\
\hline$-\mathrm{P}$ & O. sativa & + & ND & ND & Umehara et al. 2010 \\
\hline$-\mathrm{P}$ & S. lycopersicum & + & ND & ND & López-Ráez et al. 2008a, b \\
\hline$-\mathrm{P}$ & S. lycopersicum & + & ND & ND & Yoneyama et al. 2012 \\
\hline$-\mathrm{P}$ & S. bicolor & + & ND & ND & Yoneyama et al. 2007 \\
\hline$-\mathrm{P}$ & T. aestivum & + & ND & ND & Yoneyama et al. 2012 \\
\hline$-\mathrm{P}$ & L. sativa & + & ND & ND & Yoneyama et al. 2012 \\
\hline$-\mathrm{P}$ & A. sinicus & + & ND & ND & Yoneyama et al. 2012 \\
\hline$-\mathrm{P}$ & A. thaliana & + & ND & ND & Kohlen et al. 2011 \\
\hline$-\mathrm{P}$ & T. pratense & + & ND & ND & Yoneyama et al. 2012 \\
\hline$-\mathrm{P}$ & C. officinalis & + & ND & ND & Yoneyama et al. 2012 \\
\hline$-\mathrm{P}$ & L. japonicus & + & ND & ND & Liu et al. 2015 \\
\hline$-\mathrm{N}$ & M. truncatula & $=$ & ND & ND & Yoneyama et al. 2012 \\
\hline$-\mathrm{N}$ & P. sativum & + & ND & ND & Foo et al. 2013a, b \\
\hline$-\mathrm{N}$ & O. sativa & + & ND & ND & Jamil et al. 2011a; b \\
\hline$-\mathrm{N}$ & S. lycopersicum & $=$ & ND & ND & Yoneyama et al. 2012 \\
\hline$-\mathrm{N}$ & S. bicolor & + & ND & ND & Yoneyama et al. 2007 \\
\hline$-\mathrm{N}$ & S. bicolor & + & ND & ND & Yoneyama et al. 2013 \\
\hline$-\mathrm{N}$ & T. aestivum & + & ND & ND & Yoneyama et al. 2012 \\
\hline$-\mathrm{N}$ & L. sativa & + & ND & ND & Yoneyama et al. 2012 \\
\hline$-\mathrm{N}$ & A. sinicus & + & ND & ND & Yoneyama et al. 2012 \\
\hline$-\mathrm{N}$ & C. officinalis & + & ND & ND & Yoneyama et al. 2012 \\
\hline Drought & S. lycopersicum & ND & $=$ & R. irregularis & Aroca et al. 2008 \\
\hline Drought & T. aestivum & ND & - & G. etunicatum & Al-Karaki et al. 2004 \\
\hline Drought & T. aestivum & ND & + & F. mosseae & Al-Karaki et al. 2004 \\
\hline Drought & T. aestivum & ND & $=$ & G. etunicatum & Al-Karaki et al. 2004 \\
\hline Drought & T. aestivum & ND & $=$ & F. mosseae & Al-Karaki et al. 2004 \\
\hline Drought & C. lanatus & ND & + & R. irregularis & Omirou et al. 2013 \\
\hline Drought & C. lanatus & ND & + & F. mosseae & Omirou et al. 2013 \\
\hline Drought & Z. mays & ND & - & G. etunicatum & Zhu et al. 2012 \\
\hline Drought & A. majus & ND & - & G. deserticola & Asrar et al. 2012 \\
\hline Salinity & L. sativa & $-/+$ & + & R. irregularis & Aroca et al. 2013 \\
\hline Osmotic & L. japonicus & - & ND & $\mathrm{ND}$ & Liu et al. 2015 \\
\hline Low $\mathrm{T}$ & S. bicolor & ND & - & R. irregularis & Augé et al. 2004 \\
\hline Low $\mathrm{T}$ & O. sativa & $=$ & $=$ & R. irregularis & Liu et al. 2013 \\
\hline High $\mathrm{T}$ & M. truncatula & ND & + & R. irregularis & Hu et al. 2015 \\
\hline $\mathrm{Cd}$ & T. aestivum & ND & - & F. mosseae & Shahabivand et al. 2012 \\
\hline
\end{tabular}


Table 1 (continued)

\begin{tabular}{llllll}
\hline Stress & Plant & Effect on SLs & Effect on AMF colonisation & AM fungus & Reference \\
\hline $\mathrm{Cu}$ & M. truncatula & ND & - & R. irregularis & Hagerberg et al. 2011 \\
$\mathrm{Al}$ & A. virginicus & ND & - & A. morrowiae & Kelly et al. 2005 \\
$\mathrm{Al}$ & A. virginicus & ND & + & G. clarum & Kelly et al. 2005 \\
\hline
\end{tabular}

Stresses include: phosphorus starvation $(-\mathrm{P})$, nitrogen starvation $(-\mathrm{N})$, drought, salinity, low temperature (Low T), high temperature (High $\mathrm{T})$, cadmium $(\mathrm{Cd})$, copper $(\mathrm{Cu})$ and aluminium $(\mathrm{Al})$. The levels are compared with control plants (non-stressed), and are higher $(+)$, lower $(-)$ or not different $(=)$. ND not determined

sufficient $\mathrm{P}$, under $\mathrm{P}$ limitation SLs promoted lateral root development in Arabidopsis to improve P uptake (Fig. 2) (Ruyter-Spira et al. 2011). The involvement of SLs in the regulation of root architecture occurs through its crosstalk with the phytohormones auxin and ethylene (Kapulnik et al. 2011b; Koltai 2011; Ruyter-Spira et al. 2011). In Arabidopsis, the expression of the auxin receptor TRANSPORT INHIBITOR RESPONSE1 (TIR1) was increased by low P levels. Interestingly, this increase only occurred in wild-type plants but not in the SL signalling mutant (Mayzlish-Gati et al. 2012). Therefore, SLs may regulate RSA by affecting auxin sensitivity. Lateral root development and primary root growth depend on auxin influx from the polar auxin transport stream, which is mainly fed by auxin produced in the apex and young leaves (Aloni 2013; Dubrovsky et al. 2011). In Arabidopsis, GR24 application reduced the auxin level in young developing rosette leaves, resulting in a decreased leaf area (Ruyter-Spira et al. 2011). A logical explanation for this effect could be that because GR24 has an inhibitory effect on the auxin transport capacity of the polar auxin transport stream in the stem (Crawford et al. 2010), auxin levels initially accumulate, which negatively feeds back on auxin biosynthesis. Interestingly, both GR24 application and low P conditions reduced auxin transport and the activity of the auxin reporter DR5::GUS in rice root tips, suggesting that, like in Arabidopsis, SL-mediated root development
Fig. 2 Impact of phosphorus status on strigolactone production and plant development in Arabidopsis thaliana (ecotype Columbia). Phosphate (P) deficiency promotes strigolactone (SL) production in the roots, affecting plant architecture. Under these conditions, SLs are involved in reducing primary root growth, inducing lateral root density and development, and stimulating root hair elongation and density. These modifications allow the plant to increase the exploratory capacity of the soil. SLs are also transported to the shoot, where they inhibit shoot branching, hence increasing the root-to-shoot ratio

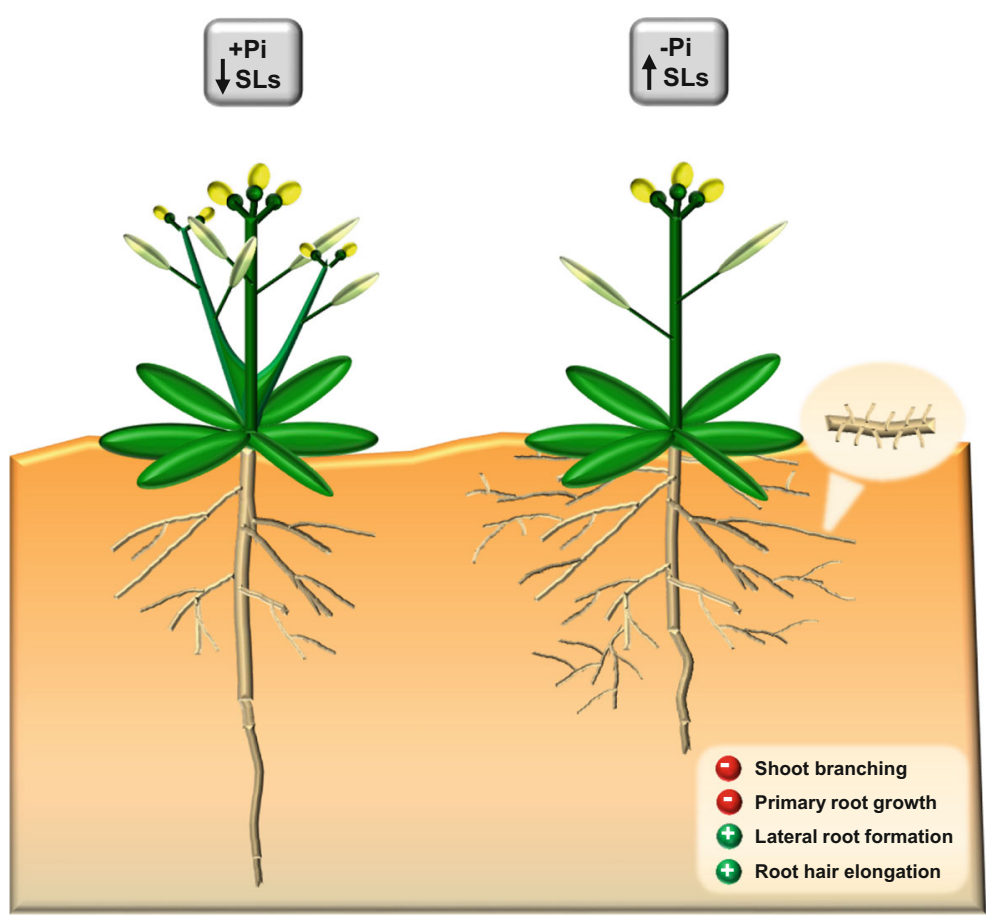


is regulated via a reduction of auxin transport from shoot to root (Sun et al. 2014). Indeed, GR24 has been shown to reduce the expression of the gene encoding the auxin efflux protein PIN1 in the stem (Crawford et al. 2010). Moreover, GR24 was found to rapidly (within $10 \mathrm{~min}$ ) induce the depletion of PIN1 from the plasma membrane of stem xylem parenchyma cells (Shinohara et al. 2013). Although GR24 application also caused a reduction of PIN1 protein levels in the provascular region of root tips (Ruyter-Spira et al. 2011), this was only observed after 6 days when seedlings were grown in the continuous presence of GR24, and is therefore likely a secondary effect due to reduced auxin import from upper parts of the plant. Still, a direct effect on auxin transport capacity in certain regions of the root tip cannot be excluded. Recently, it was indeed observed that GR24 stimulates polar localization of PIN2 in the plasma membrane of root epidermal cells (Pandya-Kumar et al. 2014). Thus, SLs seem to regulate RSA by acting as modulators of the auxin flux hereby altering auxin levels according to the environmental conditions. With respect to the interaction with ethylene, it was proposed that SLs promote its biosynthesis, which in turn induces auxin biosynthesis, transport and signalling in the roots (Stepanova and Alonso 2009). This SL-ethylene-auxin cross-talk has only been proposed for the regulation of root hair elongation (Kapulnik et al. 2011b), although it is very likely that it may also be involved in the regulation of lateral root development, as well as in other SL-mediated processes.

Although we have some ideas about how SLs act in regulating root architecture, we are still far from understanding the exact mechanism and its regulation by environmental conditions. In addition, other phytohormones such as auxin, ethylene, ABA, gibberellins and cytokinins have been shown to be involved in RSA regulation and should be included in this complex signalling network.

\section{Alternative strategies for $\mathbf{P}$ uptake: arbuscular mycorrhizas}

The soil ecosystem is one of the main factors involved in nutrient cycling and plant productivity, which is intimately related to the associated microbiota (van der Heijden et al. 2008). Root architecture is not only of great importance for the uptake of nutrients and water, it is also vital for the anchorage in the soil and the interaction with symbiotic organisms (Den Herder et al.
2010). Alternatively to the 'direct pathway' of obtaining $\mathrm{P}$ by root hairs and lateral roots, another plant strategy to improve $\mathrm{P}$ acquisition is by establishing symbiosis with certain soil microorganisms such as AM fungi, the socalled 'AM pathway' (Smith and Read 2008; Smith and Smith 2011). AM symbiosis is one of the most widespread plant associations with beneficial microorganisms. About $80 \%$ of land plants, including most agricultural and horticultural crop species, are able to establish this type of symbiosis with fungi from the phylum Glomeromycota (Barea et al. 2005; Smith and Read 2008). It is older than 450 million years and is considered a key step in the evolution of terrestrial plants (Smith and Read 2008). By this mutualistic beneficial association, the fungus obtains photoassimilates from the plant to complete its lifecycle. In turn, it helps the plant in the acquisition of water and mineral nutrients, mainly $\mathrm{P}$ and nitrogen. AM fungi are obligate biotrophs that colonize the root cortex of the host plant, forming specialized and highly branched tree-like structures called arbuscules in the cells of the host, where the nutrient exchange between the two partners takes place (Genre et al. 2013; Gutjahr and Parniske 2013). The hyphae of the fungus grow into the soil far beyond the root rhizosphere and develop an extensive hyphal network that takes up P via fungal high-affinity transporters (Harrison 2005; Smith and Smith 2011), thus acting as 'helper roots' that can search for P beyond the P depletion zone. Accordingly, symbiosis establishment is promoted under P deficiency conditions (Table 1) (Fusconi 2014; Harrison 2005; Smith and Read 2008). A stimulatory effect of nitrogen deficiency has also been reported (Table 1), although its effect seems to be generally weaker than that observed for P (Correa et al. 2014; Nouri et al. 2014). The levels of other essential mineral nutrients such as iron, potassium and calcium do not appear to exert any effect on mycorrhizal colonisation (Fusconi 2014; Nouri et al. 2014).

Mycorrhizal plants can be colonized by several different species of AM fungi, suggesting that there is little host-specificity. However, there are differences in the symbiotic efficiency of one AM species on different plant species and different AM species display different capacity of colonisation on one plant species (Smith and Read 2008). In general, AM symbiosis positively affects plant development and plant fitness, especially under unfavourable conditions. However, neutral or even negative effects on plant growth, attributed to $\mathrm{P}$ deprivation and an excessive carbon use by the AM fungus, have 
also been described (Grace et al. 2009; Li et al. 2008; Smith and Smith 2012). The negative plant response to AM colonisation has been proposed to be associated with the reduced $\mathrm{P}$ absorption capacity by the 'direct pathway' induced by the symbiosis and to a lower $\mathrm{P}$ uptake capacity by the AM fungus through the 'AM pathway' (Smith and Smith 2012). Therefore, searching for the optimal 'dance partner' is crucial for a mutualistic beneficial association.

It is well known that phytohormone homeostasis is altered during AM symbiosis establishment and functioning (Bucher et al. 2014; Foo et al. 2013a; Gutjahr 2014; Pozo et al. 2015). Some phytohormones control the early steps of the interaction regulating root morphology and preparing the plant to accommodate the fungus, others are involved in later stages controlling the extension of colonisation and/or the lifespan of the arbuscules and some hormones can be involved at the different stages of the symbiosis. Despite their regulatory functions as plant hormones, SLs were initially identified as signalling molecules in the rhizosphere, where they were shown to act as hyphal branching factors of AM fungi of the Gigasporaceae and germination stimulants in a number of AM fungi of the Glomeraceae (Akiyama et al. 2005; Besserer et al. 2006). It is proposed that plants themselves are able to actively influence the level of mycorrhizal colonisation by controlling the production of SLs depending on the $\mathrm{P}$ status (Table 1) (Foo et al. 2013b; López-Ráez et al. 2008a; Yoneyama et al. 2007, 2012). However, the existence of additional molecular signals during the early stages of the interaction has been also suggested (Balzergue et al. 2011). SL perception by a so far uncharacterized receptor in the AM fungus induces profuse hyphal growth and branching - the so-called pre-symbiotic stage -, increasing the chance of encountering the roots of the host plant and facilitating symbiosis establishment (Akiyama et al. 2005; Besserer et al. 2006). Upon recognition of the fungal partner, the plant actively accommodates the fungus within the roots (Bonfante and Genre 2010; Gutjahr and Parniske 2013), but also controls its proliferation and arbuscule development (Reinhardt 2007; Walter 2013). While the importance of SLs in the initial stages of AM fungal colonisation is well accepted, it is not clear whether they also play a role in subsequent steps of the symbiosis.

In addition to SL signalling by the plant, and also before symbiosis establishment, AM fungi produce and release diffusible compounds - Myc factors and short chitin oligomers - into the rhizosphere that act as molecular cues indicating the presence of the fungus in the vicinity of the host root and inducing the plant responses required for a successful colonisation (Bucher et al. 2014; Genre et al. 2013; Maillet et al. 2011). Myc factors consist of a mixture of sulphated and nonsulphated simple lipochito-oligosaccharides that have structural similarities with the rhizobial Nod factors (Maillet et al. 2011). Maillet and co-workers showed that these compounds are not only symbiotic cues that stimulate AM establishment, but also act as plant growth regulators affecting the formation of lateral roots, the AM fungal entry sites. Interestingly, it has been demonstrated that the addition of GR24 elicits the production of short chitin oligomers in the AM fungus Rhizophagus irregularis (formerly known as Glomus intraradices) (Genre et al. 2013). Therefore, it seems that both partners mutually sense each other and that they respond accordingly. Indeed, using a split-root system with tomato plants, we have recently observed that SL production was higher in roots inoculated with $R$. irregularis compared with non-inoculated roots during the early stages of interaction/colonisation (López-Ráez et al. 2015). This observation suggests that the plant is really sensing the presence of the fungus and that it actively reacts to favour fungal development and symbiosis establishment by promoting SL production. SLs also promote lateral root formation (Ruyter-Spira et al. 2011), therefore, this initial fungal-mediated induction of SLs may serve to increase the number of colonisation sites.

The characterization and a better knowledge on the specificity of these pre-symbiotic signals should pave the way for the development of new environmentallyfriendly agricultural strategies based on AM symbiosis.

\section{Effect of other abiotic stresses on SL production and $\mathrm{AM}$ symbiosis}

In nature, plants are generally exposed to combinations of unfavourable environmental conditions. Besides a better nutrient supply, AM symbiosis provides also increased tolerance against other abiotic stresses such as heavy metals, drought and salinity (Aroca et al. 2013; Evelin and Kapoor 2014; Li et al. 2014; Ruiz-Lozano et al. 2012; Singh et al. 2011). So far, there are, however, no indications that these stresses also have an (positive) effect on symbiosis establishment, in contrast to P shortage. 
Water-related stresses

In recent years, harmful effects of water-related stresses such as drought and salinity are rising dangerously, having a major impact on plant growth and development, and being the most important factors limiting crop productivity (Albacete et al. 2014; Sunil Kumar and Garampalli 2013). Moreover, global change is contributing to spread these problems worldwide (Chaves and Oliveira 2004). Therefore, improving the yield under these stress conditions is a major goal nowadays. A concept associated to the adaptation to water related stresses is the water use efficiency (WUE), defined as the amount of dry matter or harvestable yield produced per unit of water. AM symbiosis has the capacity to alter root hydraulic properties, thus helping the plant in the uptake of water under unfavourable conditions. As a consequence, mycorrhizal plants show a higher WUE and root turgor, alleviating the negative effects of water shortage on plant physiology (Al-Karaki et al. 2004; Augé et al. 2015; Bárzana et al. 2014; Li et al. 2014; Wu and Xia 2006). This effect has been associated to an improved nutrient uptake in mycorrhizal plants, which promotes the photosynthetic capacity and growth ( $\mathrm{Li}$ et al. 2014; Smith et al. 2010). However, the extent of the benefits depends on both the host plant and AM fungal species (Augé et al. 2015). On the other hand, the expression of genes encoding aquaporins is altered in mycorrhizal plants which may play a role in the improved water status in AM plants, although their regulation depends on the type and severity of the stress (Aroca et al. 2007; Bárzana et al. 2014; Uehlein et al. 2007).

Even though it is evident that under drought or salinity AM plants perform better than nonmycorrhizal ones, the effects of water-related stresses in AM symbiosis establishment is not clear and sometimes contradictory (Table 1). Interestingly, an increased SL production under salt stress in the presence of the AM fungus $R$. irregularis was shown in lettuce (Table 1) (Aroca et al. 2013), which might indicate the active promotion of symbiosis establishment. Similarly, the promotion of SL production in mycorrhizal plants has also been observed in lettuce and tomato under drought stress (López-Ráez et al., unpublished data). In both cases, the induction of SLs occurred in a dose-dependent manner, with the greatest increase under the strongest stress. A different behaviour was observed in the absence of mycorrhization under salinity or drought, where the stress reduced SL production also in a dosedependent manner (Table 1) (Aroca et al. 2013; López-Ráez et al., unpublished data). A negative effect on SL production in the absence of mycorrhizal colonization has also been observed in Lotus japonicus plants subjected to osmotic stress (Table 1) (Liu et al. 2015). These results might suggest that plants sense the presence of the AM fungus and that they respond by producing SLs under unfavourable conditions to improve colonization. A relationship between drought and salinity with SLs has also been proposed in the non-mycorrhizal plant Arabidopsis (Ha et al. 2014). Here, a positive effect of SLs on the tolerance to these stresses was observed. Ha and co-workers showed that SL-deficient mutants were hypersensitive to drought and salt stress, and that this phenotype was rescued by exogenous GR24 application. The authors also showed that wild-type plants treated with GR24 were more tolerant to these stresses than untreated plants (Ha et al. 2014). The results from lettuce, tomato and Arabidopsis suggest a different behaviour between mycorrhizal and non-mycorrhizal plants in response to water-related stresses. However, more knowledge is required to decipher how SL regulation is involved in these stress responses and how this regulation is affected by and/or affects AM symbiosis.

As in previous cases, the alteration in the phytohormone homeostasis in mycorrhizal plants has been implicated in the enhanced tolerance against these stresses and here, ABA signalling is the most studied pathway (Calvo-Polanco et al. 2013; Ruiz-Lozano et al. 2012). ABA is considered as the 'stress hormone', as it accumulates rapidly in response to drought and salinity (Hong et al. 2013). Interestingly, a reduction in ABA content has been reported in mycorrhizal roots (Aroca et al. 2008, 2013; Duan et al. 1996; Estrada-Luna and Davies 2003; Fernández et al. 2014), suggesting that AM plants are less stressed than non-mycorrhizal ones. In contrast, when stressed, an increase in ABA content is generally observed in mycorrhizal plants (Aroca et al. 2013; Calvo-Polanco et al. 2013), which has been associated with priming for increased stress tolerance. ABA is also necessary for a proper establishment and functioning of the AM symbiosis. It positively regulates arbuscule development and functionality (HerreraMedina et al. 2007; Martín-Rodríguez et al. 2011). Thus, the increased ABA levels in stressed plants would serve to promote tolerance against stresses, but also to 
enhance and maintain the symbiosis. Interestingly, there also seems to be a relationship between ABA and SLs. It was shown that the tomato ABA-deficient mutants notabilis, sitiens and flacca, blocked at different steps of the ABA biosynthetic pathway, and wild-type plants treated with specific ABA inhibitors produced less SLs (López-Ráez et al. 2010b). Moreover, a correlation between ABA and SL levels was reported in mycorrhizal lettuce plants subjected to salt stress (Aroca et al. 2013). It seems, thus, that SLs play a dual role under stress conditions. On the one hand, they act as signalling molecules in the rhizosphere favouring AM symbiosis. On the other hand, they form part of the integrative plant hormonal response to unfavourable conditions, interacting with $\mathrm{ABA}$ and probably with other stressrelated phytohormones to maintain the symbiosis at an optimal level.

\section{Other stresses}

Studies on the influence of other abiotic stresses on AM symbiosis are scarce and usually contradictory. A negative effect of low temperature was reported in wheat and sorghum, while no effect was observed in rice (Table 1) (Augé et al. 2004; Hetrick et al. 1984; Liu et al. 2013). Conversely, a positive effect of high temperature on the symbiosis has recently been reported in Medicago truncatula (Table 1) (Hu et al. 2015). In relation to heavy metals, an inhibitory influence of cadmium on the AM fungus Funneliformis mosseae (formerly Glomus mosseae) was detected in wheat (Table 1), although mycorrhizal plants were more tolerant than non-mycorrhizal (Shahabivand et al. 2012). A negative effect on AM colonisation was also observed for copper in maize (Table 1) (Hagerberg et al. 2011). Aluminium affected different species of AM fungi in broomsedge (Andropogon virginicus), ranging from a negative to a positive effect, depending on the concentration (Kelly et al. 2005). As far as we know, no data about the influence of these abiotic stresses on SL biosynthesis have been reported so far. In any case, it seems that, unlike for the nutritional stress, the effects of other abiotic stresses on SLs and AM symbiosis differ between different species of host plants and AM fungi and probably depend on the severity of the stress. Further research is required to ascertain whether this is the case, but also to understand whether and how these stresses regulate SL production and AM symbiosis, and vice versa.

\section{SLs in other plant rhizosphere interactions}

Plant-microbe interactions

The rhizosphere is the narrow soil zone surrounding plant roots and constitutes a very dynamic environment. In addition to AM fungi, it harbours many different organisms and is highly influenced by plant root exudates (Badri et al. 2009; Bais et al. 2006; Barea et al. 2005). Recently, a role for SLs in another important beneficial plant-microorganism association in the rhizosphere - nodulation - was described (Fig. 1) (De Cuyper et al. 2015; Foo and Davies 2011; Soto et al. 2010). Nodulation is established between legumes and certain rhizobacteria collectively known as rhizobia, and dates back about 60 million years (Garg and Geetanjali 2007). This symbiosis is characterized by the development of nodules on the plant roots, where rhizobia fix atmospheric nitrogen, thus improving plant nutrition. Nodules provide the proper micro-environment for nitrogen fixation and nutrient exchange with the host plant in return for photoassimilates (Garg and Geetanjali 2007; Oldroyd and Downie 2008). Accordingly, an increase in SL production under nitrogen deficiency has been shown to occur in pea (Table 1) (Foo et al. 2013b), but also in some non-legume plant species such as rice, sorghum, wheat and lettuce (Table 1) (Jamil et al. 2011a; Yoneyama et al. 2007, 2012). Just as for AM symbiosis, nodulation requires a high degree of coordination between the two partners based on a coordinated molecular communication (Murray 2011; Oldroyd and Downie 2008). However, here SLs do not seem to act as host detection signals (Soto et al. 2010). The chemical dialogue is initiated with the production and exudation of specific flavonoids by the host plant (Badri et al. 2009; Hassan and Mathesius 2012). These flavonoids act as attractants for rhizobial bacteria and inducers of Nod factor biosynthesis, which are structurally similar to the AM fungal Myc factors (see above) (Maillet et al. 2011). Although SLs do not seem to be involved in the pre-symbiotic stage, it has been shown that they are required for optimal nodule number formation (Foo and Davies 2011). Foo and Davies observed that the pea SL-deficient mutant rms 1 (mutated in CCD8) established about $40 \%$ less nodules than the corresponding wild-type, and that the phenotype was partially rescued by exogenous GR24 application. Moreover, they showed that GR24 increased the nodule number in wild-type plants (Foo and Davies 2011). More recently, 
in Medicago truncatula it was shown that the effect of GR24 on nodule number is dose-dependent (De Cuyper et al. 2015). De Cuyper and co-workers showed that low concentrations $(0.1 \mu \mathrm{M})$ of GR24 had a positive effect, while higher concentrations negatively affected the number of nodules. Therefore, SLs play an important role, albeit different, in two of the most important beneficial interactions in the rhizosphere, further confirming their biological and ecological relevance.

The implication of SLs in other plant-microbe interactions below-ground is not clear. Steinkellner and coworkers showed no response after GR24 application in other beneficial fungal species such as ectomycorrhizal fungi, Trichoderma and Piriformospora indica (Steinkellner et al. 2007). Regarding fungal pathogens, contradictory data have been reported. On the one hand, no direct effect was observed in fungal pathogens such as Rhizoctonia solani, Fusarium oxysporum f. sp. licopersici, Verticillium dahliae or Botrytis cinerea at low GR24 concentrations (Steinkellner et al. 2007; Torres-Vera et al. 2014). On the other hand, a negative effect on growth was detected for fungi such as F. oxysporum f. sp. melonis, F. oxysporum f. sp. mango, Sclerotinia sclerotiorum or $B$. cinerea at higher GR24 concentrations (Dor et al. 2011a). Dor and co-workers also observed increased hyphal branching activity in F. oxysporum f. sp. melonis and S. sclerotiorum (Dor et al. 2011a). Thus, it seems that the effect of SLs on microbes depends on the fungal species and SL concentration.

Root parasitic plants

Long before the discovery of their function as phytohormones and signalling cues for symbiotic plantmicroorganism interactions in the rhizosphere, SLs were discovered to be germination stimulants of root parasitic plants of the Orobanchaceae, including the genera Striga (witchweeds), Orobanche and Phelipanche (broomrapes) (Fig. 1) (Bouwmeester et al. 2003; Cook et al. 1966). These obligate parasitic weeds are some of the most damaging agricultural pests, affecting important crops such as rice, maize, sorghum, legumes, tobacco, sunflower and tomato worldwide. They can cause up to $70 \%$ losses in crop yields (Gressel et al. 2004; Joel et al. 2007; Parker 2009). Broomrapes are generally found in more temperate regions such as southern Europe, the Mediterranean area, Central Asia and the Americas, and witchweeds appear in warmer areas, mainly in Africa (Parker 2009). Although these parasites affect different hosts in different parts of the world, their lifecycles are broadly similar, starting with seed germination in response to SLs (López-Ráez et al. 2009; Xie et al. 2010). Upon germination, they attach to the roots of the host plant through a specialized organ called haustorium, and acquire all the nutrients and water they need to complete their lifecycle (Bouwmeester et al. 2003; Estabrook and Yoder 1998). After emergence, they produce a large amount of seeds, increasing the seed bank in the soil, which is one of the major problems in the control of these parasites (López-Ráez et al. 2009; Xie et al. 2010). In addition, most of their life cycle occurs below-ground, making diagnosis difficult such that the parasites usually have already inflicted irreversible damage. As a consequence, these parasitic weeds are difficult to control. Cultural measures such as hand weeding, improvement of soil fertility, crop rotation, sanitation, fumigation or solarisation are being used, but without the desirable success (Joel et al. 2007; Rispail et al. 2007; Scholes and Press 2008). Therefore, new strategies and/or a combination of different methods for a more effective control against these agricultural pests are needed.

\section{Agronomical implications of SL signalling}

AM symbiosis as biofertilizer and biocontrol agent

The 'Green Revolution' that took place after the Second World War, was accompanied by over-exploitation of the soil and an excessive use and abuse of agrochemicals such as fertilizers, pesticides and herbicides. Nowadays, due to the public concern about the side effects of these chemicals, there is increasing interest in finding alternatives for more environmentally friendly agriculture. AM symbiosis generally improves the growth of its host plant by facilitating water and mineral nutrient uptake, particularly under stress conditions, although negative effects have also been described, especially in cereals (Grace et al. 2009; Li et al. 2008). Moreover, AM fungi are widely distributed and can colonise most agricultural and horticultural crop species. Indeed, AM fungi are occasionally being used as biofertilisers for enhancing plant growth and biomass production, although much less than conventional fertilisers (Barea et al. 2005; Duhamel and Vandenkoornhuyse 2013; Gianinazzi et al. 2010). Considering the fact that AM symbiosis does also 
impact the plant's ability to overcome abiotic and biotic stresses, they may not only serve to improve plant nutrition, but also as a biocontrol strategy against different environmental stresses.

SLs are important for AM symbiosis establishment (Akiyama et al. 2005; Besserer et al. 2006; Foo et al. 2013b; Gomez-Roldan et al. 2008; Kohlen et al. 2012). Therefore, breeding for cultivars with high SL production potentially is a strategy to improve mycorrhizal colonisation under agronomical conditions. Alternatively, this could be achieved by the exogenous application of natural SLs or synthetic analogues. On the other hand, we have described above that stress conditions such as nutrient deficiency, drought or salinity influence SL biosynthesis. Thus, another way of promoting AM symbiosis might be by applying controlled stress conditions that do not negatively affect the plant too much. However, when applying these approaches we should keep in mind that SLs are also germination stimulants of root parasitic plants and that they are involved in multiple physiological functions within the plant. In addition, each plant species is producing a different blend of SLs, which may also depend on the developmental stage and environmental conditions (Ćavar et al. 2014; Xie et al. 2010), although very little is known about their specificity. Therefore, a better understanding of their structure-activity relationship and biology is essential prior to its application. Some progress has already been made, and the effect of structural differences between SLs on AM fungal branching activity, parasitic weed seed germination and shoot branching have been demonstrated (Akiyama et al. 2010; Boyer et al. 2012, 2014; Yoneyama et al. 2009). Interestingly, SL specificity in transport in and ex planta has also been reported (Kohlen et al. 2012). Kohlen and co-workers showed that certain SLs are mainly exuded into the rhizosphere, while others are preferentially loaded into the xylem and transported to the shoot. Elucidation of SLs potentially specific for host plant-AM fungus interaction will definitively contribute to a better implementation of AM symbiosis in agro-ecosystems.

Management strategies against root parasitic plants based on SLs

As mentioned above, root parasitic plants are difficult to control because most of their life cycle occurs belowground. Since these parasites exert the greatest damage prior to their emergence, such strategies should mainly focus on the initial steps of infection, particularly seed germination triggered by SLs and attachment (Fernández-Aparicio et al. 2011; López-Ráez et al. 2009; Yoder and Scholes 2010). Breeding for cultivars with reduced SL production and/or exudation could be a suitable strategy to combat these pests. Indeed, it was shown that the low SL producing tomato mutants SlORT1 and high pigment-2 $\left(\mathrm{hp}-2^{d g}\right)$ are more resistant to infection by different Orobanche and Phelipanche species than the corresponding wild-types (Dor et al. 2011b; López-Ráez et al. 2008b). Genetic variation for low SL production has also been described in other important crops such as sorghum, rice and faba bean (Dor et al. 2011b; Fernández-Aparicio et al. 2014; Jamil et al. 2011b; López-Ráez et al. 2008b; Satish et al. 2012). In sorghum, this genetic variation was used to breed for Striga resistant varieties for use in Africa (Ejeta 2007). In rice, cultivars with lower SL production also displayed reduced infection by Striga hermonthica (Jamil et al. 2011b). Similarly, root exudates from faba bean lines resistant against Orobanche and Phelipanche spp. showed low levels of SLs (Fernández-Aparicio et al. 2014). An alternative approach to obtain resistant plants by reducing SLs is through biotechnology, targeting biosynthesis genes. Indeed, $c c d 7$ and $c c d 8$ mutants from different plant species showed a reduced production of SLs (Drummond et al. 2009; GomezRoldan et al. 2008; Kohlen et al. 2012; Ledger et al. 2010; Umehara et al. 2008; Vogel et al. 2010). Genetic engineering using RNAi technology on the tomato $C C D 7$ and $C C D 8$ genes resulted in a significant reduction in SLs, which correlated with a lower germination of P. ramosa seeds (Kohlen et al. 2012; Vogel et al. 2010) and decreased $P$. ramosa infection of the transgenic tomato lines in pot experiments (Kohlen et al. 2012).

AM symbiosis to control root parasitic plants

The fact that SLs play a dual role in the rhizosphere as host detection cues for these parasites and for AM fungi also opens up another possibility to develop new control strategies. It was shown that AM symbiosis in cultivars of maize and sorghum led to a reduction in S. hermonthica infection in the field (Lendzemo et al. 2005). Lendzemo and co-workers proposed that this reduced infection was caused, at least in part, by a reduction in the production of SLs in mycorrhizal plants. Similarly, exudates from AMcolonized lettuce, pea, and tomato plants induced less 
germination of Orobanche and Phelipanche spp. seeds compared with non-colonized plants (Aroca et al. 2013; Fernández-Aparicio et al. 2010; LópezRáez et al. 2011a). In the case of tomato, it was shown that this reduced germination was caused by a decrease in the production of SLs and that this depends on a fully established symbiosis (LópezRáez et al. 2011a). This down-regulation of SL production likely represents a mechanism to prevent excessive colonisation that could be metabolically costly for the plant, a mechanism known as autoregulation (Staehelin et al. 2011). The results from maize, sorghum, pea, tomato, sunflower and lettuce suggest that the AM-associated decrease in SLs is conserved across the plant kingdom. Since AM fungi colonize roots of most agricultural and horticultural species, AM symbiosis could be used as an environmentally-friendly biocontrol strategy against these root parasites. Interestingly, these crops would also take advantage of all the other well-known benefits of the symbiosis.

All these examples indicate that the development of new strategies to improve crop production and reduce pest infestation by targeting SLs is feasible. However, since SLs are also phytohormones regulating different processes within the plant and affect other beneficial associations in the rhizosphere, the effect of altering SL production should be carefully evaluated before application in agro-ecosystems to avoid possible undesired side-effects.

\section{Future perspectives in SL research and their use in agriculture}

Experimental evidence illustrates the biological and ecological importance of SLs in the rhizosphere. Unravelling new roles and functions for the different SLs in and ex planta is therefore exciting and promising. Their multifunctional nature opens up a wide range of possibilities for potential applications in agriculture. A number of studies points to differences in biological specificity of individual SLs, although we are still far from a full understanding of how this mechanistically works. Further research on the requirements for specific SLs in the different biological processes should expand our understanding about the biological processes occurring belowground (Box 1). Moreover, an in-depth knowledge of the mechanisms that regulate SL production and release, and about how they are affected by different environmental conditions is required (Box 1) in order to allow us to exploit the full potential for these signalling molecules in agriculture.

Box 1. Outstanding research questions.

- Which enzymes catalyse the decoration of the SLs, and where are they expressed?

- How is the production of SLs affected by environmental factors?

- What are the structural requirements of SLs for their different biological functions?

- What are the receptors for SLs in AM fungi?

- What is the lifespan of SLs in the rhizosphere?

- What is the exact mechanism by which SLs regulate root architecture and how are other plant hormones involved?

Acknowledgments Research of the authors is supported by the grants AGL2012-39923 from the National R\&D Plan of the Ministry of Science and Innovation (MINCIN) and the Netherlands Organization for Scientific Research (NWO; VICI grant, 865.06.002 to HB). BAJ was supported by an anonymous private donor who provided financial support to this project via the Wageningen University Fund. We are thankful for the scientific exchange between partners in the COST action FA1206 'Strigolactones biological roles and applications' (STREAM).

\section{References}

Abe S, Sado A, Tanaka K, Kisugi T, Asami K, Ota S, Kim HI, Yoneyama K, Xie X, Ohnishi T, Seto Y, Yamaguchi S, Akiyama K, Yoneyama K, Nomura T (2014) Carlactone is converted to carlactanoic acid by MAX1 in Arabidopsis and its methyl ester can directly interact with AtD14 in vitro. Proc Natl Acad Sci U S A 111:18084-18089

Agusti J, Herold S, Schwarz M, Sanchez P, Ljung K, Dun EA, Brewer PB, Beveridge CA, Sieberer T, Sehr EM, Greb T (2011) Strigolactone signaling is required for auxindependent stimulation of secondary growth in plants. Proc Natl Acad Sci U S A 108:20242-20247

Akiyama K, Matsuzaki K, Hayashi H (2005) Plant sesquiterpenes induce hyphal branching in arbuscular mycorrhizal fungi. Nature 435:824-827

Akiyama K, Ogasawara S, Ito S, Hayashi H (2010) Structural requirements of strigolactones for hyphal branching in AM fungi. Plant Cell Physiol 51:1104-1117

Albacete AA, Martínez-Andújar C, Pérez-Alfocea F (2014) Hormonal and metabolic regulation of source-sink relations under salinity and drought: from plant survival to crop yield stability. Biotechnol Adv 32:12-30

Alder A, Jamil M, Marzorati M, Bruno M, Vermathen M, Bigler P, Ghisla S, Bouwmeester H, Beyer P, Al-Babili S (2012) The 
path from $\beta$-carotene to carlactone, a strigolactone-like plant hormone. Science 335:1348-1351

Al-Karaki G, McMichael B, Zak J (2004) Field response of wheat to arbuscular mycorrhizal fungi and drought stress. Mycorrhiza 14:263-269

Aloni R (2013) Role of hormones in controlling vascular differentiation and the mechanism of lateral root initiation. Planta 238:819-830

Arite T, Kameoka H, Kyozuka J (2012) Strigolactone positively controls crown root elongation in rice. J Plant Growth Regul 31:165-172

Aroca R, Porcel R, Ruiz-Lozano JM (2007) How does arbuscular mycorrhizal symbiosis regulate root hydraulic properties and plasma membrane aquaporins in Phaseolus vulgaris under drought, cold or salinity stresses? New Phytol 173:808-816

Aroca R, Del Mar AM, Vernieri P, Ruiz-Lozano JM (2008) Plant responses to drought stress and exogenous ABA application are modulated differently by mycorrhization in tomato and an ABA-deficient mutant (sitiens). Microb Ecol 56:704-719

Aroca R, Ruiz-Lozano JM, Zamarreño TM, Paz JA, García-Mina JM, Pozo MJ, López-Ráez JA (2013) Arbuscular mycorrhizal symbiosis influences strigolactone production under salinity and alleviates salt stress in lettuce plants. J Plant Physiol 170:47-55

Asrar AA, Abdel-Fattah GM, Elhindi KM (2012) Improving growth, flower yield, and water relations of snapdragon (Antirhinum majus L.) plants grown under well-watered and water-stress conditions using arbuscular mycorrhizal fungi. Photosynthetica 50:305-31

Augé RM, Moore JL, Sylvia DM, Cho K (2004) Mycorrhizal promotion of host stomatal conductance in relation to irradiance and temperature. Mycorrhiza 14:85-92

Augé RM, Toler HD, Saxton AM (2015) Arbuscular mycorrhizal symbiosis alters stomatal conductance of host plants more under drought than under amply watered conditions: a metaanalysis. Mycorrhiza 25:13-24

Badri DV, Weir TL, van der Lelie D, Vivanco JM (2009) Rhizosphere chemical dialogues: plant-microbe interactions. Curr Opin Biotechnol 20:642-650

Bais HP, Weir TL, Perry LG, Gilroy S, Vivanco JM (2006) The role of root exudates in rhizosphere interactions with plants and other organisms. Annu Rev Plant Biol 57:233-266

Balzergue C, Puech-Pagès V, Bécard G, Rochange SF (2011) The regulation of arbuscular mycorrhizal symbiosis by phosphate in pea involves early and systemic signalling events. J Exp Bot 62:1049-60

Barea JM, Pozo MJ, Azcon R, Azcon-Aguilar C (2005) Microbial co-operation in the rhizosphere. J Exp Bot 56:1761-1778

Bárzana G, Aroca R, Bienert GP, Chaumont F, Ruiz-Lozano JM (2014) New insights into the regulation of aquaporins by the arbuscular mycorrhizal symbiosis in maize plants under drought stress and possible implications for plant performance. Mol Plant-Microbe Interact 27:349-363

Besserer A, Puech-Pages V, Kiefer P, Gomez-Roldan V, Jauneau A, Roy S, Portais JC, Roux C, Becard G, Sejalon-Delmas N (2006) Strigolactones stimulate arbuscular mycorrhizal fungi by activating mitochondria. PLoS Biol 4:1239-1247

Bonfante P, Genre A (2010) Mechanisms underlying beneficial plant-fungus interactions in mycorrhizal symbiosis. Nat Commun 1:1-11
Bonneau L, Huguet S, Wipf D, Pauly N, Truong HN (2013) Combined phosphate and nitrogen limitation generates a nutrient stress transcriptome favorable for arbuscular mycorrhizal symbiosis in Medicago truncatula. New Phytol 199:188-202

Bouwmeester HJ, Matusova R, Zhongkui S, Beale MH (2003) Secondary metabolite signalling in host-parasitic plant interactions. Curr Opin Plant Biol 6:358-364

Bouwmeester HJ, Roux C, López-Ráez JA, Bécard G (2007) Rhizosphere communication of plants, parasitic plants and AM fungi. Trends Plant Sci 12:224-230

Boyer F-D, Germain ADS, Pillot J-P, Pouvreau J-B, Chen VX, Ramos S, Stevenin A, Simier P, Delavault P, Beau J-M, Rameau C (2012) Structure-activity relationship studies of strigolactonerelated molecules for branching inhibition in garden pea: molecule design for shoot branching. Plant Physiol 159:1524-1544

Boyer FD, De Saint GA, Pouvreau JB, Clavé G, Pillot JP, Roux A, Rasmussen A, Depuydt S, Lauressergues D, Frei Dit Frey N, Heugebaert TSA, Stevens CV, Geelen D, Goormachtig S, Rameau C (2014) New strigolactone analogs as plant hormones with low activities in the rhizosphere. Mol Plant 7:675-690

Bucher M, Hause B, Krajinski F, Küster H (2014) Through the doors of perception to function in arbuscular mycorrhizal symbioses. New Phytol 204:833-840

Calvo-Polanco M, Sánchez-Romera B, Aroca R (2013) Arbuscular mycorrhizal fungi and the tolerance of plants to drought and salinity. In: Aroca R (ed) Symbiotic endophytes. Springer, Berlin Heidelberg, pp 271-288

Cardoso C, Zhang Y, Jamil M, Hepworth J, Charnikhova T, Dimkpa SO, Meharg C, Wright MH, Liu J, Meng X, Wang Y, Li J, McCouch SR, Leyser O, Price AH, Bouwmeester HJ, Ruyter-Spira C (2014) Natural variation of rice strigolactone biosynthesis is associated with the deletion of two MAX1 orthologs. Proc Natl Acad Sci U S A 111:2379-2384

Ćavar S, Zwanenburg B, Tarkowski P (2014) Strigolactones: occurrence, structure, and biological activity in the rhizosphere. Phytochem Rev. doi:10.1007/s11101-014-9370-4

Challis RJ, Hepworth J, Mouchel C, Waites R, Leyser O (2013) A role for More Axillary Growth1 (MAX1) in evolutionary diversity in strigolactone signaling upstream of MAX2. Plant Physiol 161:1885-1902

Chaves MM, Oliveira MM (2004) Mechanisms underlying plant resilience to water deficits: prospects for water-saving agriculture. J Exp Bot 55:2365-2384

Chevalier F, Pata M, Nacry P, Doumas P, Rossignol M (2003) Effects of phosphate availability on the root system architecture: large-scale analysis of the natural variation between Arabidopsis accessions. Plant Cell Environ 26:1839-1850

Chevalier F, Nieminen K, Sánchez-Ferrero JC, Rodríguez ML, Chagoyen M, Hardtke CS, Cubas P (2014) Strigolactone promotes degradadion of DWARF14, and $\alpha / \beta$ hydrolase essential for strigolactone signaling in Arabidopsis. Plant Cell 26:1134-1150

Cook CE, Whichard LP, Turner B, Wall ME, Egley GH (1966) Germination of witchweed (Striga lutea Lour.): isolation and properties of a potent stimulant. Science 154:1189-1190

Cordell D, Drangert JO, White S (2009) The story of phosphorus: global food security and food for thought. Glob Environ Chang 19:292-305

Correa A, Cruz C, Pérez-Tienda J, Ferrol N (2014) Shedding light onto nutrient responses of arbuscular mycorrhizal plants: nutrient interactions may lead to unpredicted outcomes of the symbiosis. Plant Sci 221-222:29-41 
Crawford S, Shinohara N, Sieberer T, Williamson L, George G, Hepworth J, Müller D, Domagalska MA, Leyser O (2010) Strigolactones enhance competition between shoot branches by dampening auxin transport. Development 137:2905-2913

De Cuyper C, Fromentin J, Yocgo RE, De Keyser A, Guillotin B, Kunert K, Boyer FD, Goormachtig S (2015) From lateral root density to nodule number, the strigolactone analogue GR24 shapes the root architecture of Medicago truncatula. J Exp Bot 66:137-146

Den Herder G, Van Isterdael G, Beeckman T, De Smet I (2010) The roots of a new green revolution. Trends Plant Sci 15: 600-607

Dor E, Joel DM, Kapulnik Y, Koltai H, Hershenhorn J (2011a) The synthetic strigolactone GR24 influences the growth pattern of phytopathogenic fungi. Planta 234:419-427

Dor E, Yoneyama K, Wininger S, Kapulnik Y, Yoneyama K, Koltai H, Xie XN, Hershenhorn J (2011b) Strigolactone deficiency confers resistance in tomato line SL-ORT1 to the parasitic weeds Phelipanche and Orobanche spp. Phytopathology 101:213-222

Drummond RSM, Marcela Martínez-Sánchez N, Janssen BJ, Templeton KR, Simons JL, Quinn BD, Karunairetnam S, Snowden KC (2009) Petunia hybrida CAROTENOID CLEAVAGE DIOXYGENASE7 is involved in the production of negative and positive branching signals in petunia. Plant Physiol 151:1867-1877

Duan X, Neuman DS, Reiber JM, Green CD, Saxton AM, Augé RM (1996) Mycorrhizal influence on hydraulic and hormonal factors implicated in the control of stomatal conductance during drought. J Exp Bot 47:1541-1550

Dubrovsky JG, Napsucialy-Mendivil S, Duclercq J, Cheng Y, Shishkova S, Ivanchenko MG, Friml J, Murphy AS, Benková E (2011) Auxin minimum defines a developmental window for lateral root initiation. New Phytol 191:970-983

Duhamel M, Vandenkoornhuyse P (2013) Sustainable agriculture: possible trajectories from mutualistic symbiosis and plant neodomestication. Trends Plant Sci 18:597-600

Dun EA, Brewer PB, Beveridge CA (2009) Strigolactones: discovery of the elusive shoot branching hormone. Trends Plant Sci 14:364-372

Ejeta G (2007) Breeding for Striga resistance in sorghum: exploitation of an intricate host-parasite biology. Crop Sci 47: S216-S227

Estabrook EM, Yoder JI (1998) Plant-plant communications: rhizosphere signaling between parasitic angiosperms and their hosts. Plant Physiol 116:1-7

Estrada-Luna AA, Davies FT Jr (2003) Arbuscular mycorrhizal fungi influence water relations, gas exchange, abscisic acid and growth of micropropagated chile ancho pepper (Capsicum annuum) plantlets during acclimatization and post-acclimatization. J Plant Physiol 160:1073-1083

Evelin H, Kapoor R (2014) Arbuscular mycorrhizal symbiosis modulates antioxidant response in salt-stressed Trigonella foenum-graecum plants. Mycorrhiza 24:197-208

Fernández I, Merlos M, López-Ráez JA, Martínez-Medina A, Ferrol N, Azcón C, Bonfante P, Flors V, Pozo MJ (2014) Defense related phytohormones regulation in arbuscular mycorrhizal symbioses depends on the partner genotypes. J Chem Ecol 40:791-803

Fernández-Aparicio M, García-Garrido JM, Ocampo JA, Rubiales D (2010) Colonisation of field pea roots by arbuscular mycorrhizal fungi reduces Orobanche and Phelipanche species seed germination. Weed Res 50:262-268

Fernández-Aparicio M, Westwood JH, Rubiales D (2011) Agronomic, breeding, and biotechnological approaches to parasitic plant management through manipulation of germination stimulant levels in agricultural soils. Botany 89:813-826

Fernández-Aparicio M, Kisugi T, Xie X, Rubiales D, Yoneyama K (2014) Low strigolactone root exudation: a novel mechanism of broomrape (Orobanche and Phelipanche spp.) resistance available for faba bean breeding. J Agric Food Chem 62:7063-7071

Foo E, Davies NW (2011) Strigolactones promote nodulation in pea. Planta 243:1073-1081

Foo E, Ross JJ, Jones WT, Reid JB (2013a) Plant hormones in arbuscular mycorrhizal symbioses: an emerging role for gibberellins. Ann Bot 111:769-779

Foo E, Yoneyama K, Hugill CJ, Quittenden LJ, Reid JB (2013b) Strigolactones and the regulation of pea symbioses in response to nitrate and phosphate deficiency. Mol Plant 6:76-87

Fusconi A (2014) Regulation of root morphogenesis in arbuscular mycorrhizae: what role do fungal exudates, phosphate, sugars and hormones play in lateral root formation? Ann Bot 113:19-33

Garg N, Geetanjali (2007) Symbiotic nitrogen fixation in legume nodules: process and signaling. A review. Agron Sustain Dev 27:59-68

Genre A, Chabaud M, Balzergue C, Puech-Pagès V, Novero M, Rey T, Fournier J, Rochange S, Bécard G, Bonfante P, Barker DG (2013) Short-chain chitin oligomers from arbuscular mycorrhizal fungi trigger nuclear $\mathrm{Ca} 2+$ spiking in Medicago truncatula roots and their production is enhanced by strigolactone. New Phytol 198:190-202

Gianinazzi S, Gollotte A, Binet MN, van Tuinen D, Redecker D, Wipf D (2010) Agroecology: the key role of arbuscular mycorrhizas in ecosystem services. Mycorrhiza 20:519-530

Goldwasser Y, Yoneyama K, Xie X, Yoneyama K (2008) Production of strigolactones by Arabidospsis thaliana responsible for Orobanche aegyptiaca seed germination. Plant Growth Regul 55:21-28

Gomez-Roldan V, Fermas S, Brewer PB, Puech-Pagés V, Dun EA, Pillot JP, Letisse F, Matusova R, Danoun S, Portais JC, Bouwmeester H, Bécard G, Beveridge CA, Rameau C, Rochange SF (2008) Strigolactone inhibition of shoot branching. Nature 455:189-194

Grace EJ, Cotsaftis O, Tester M, Smith FA, Smith SE (2009) Arbuscular mycorrhizal inhibition of growth in barley cannot be attributed to extent of colonization, fungal phosphorus uptake or effects on expression of plant phosphate transporter genes. New Phytol 181:938-949

Gressel J, Hanafi A, Head G, Marasas W, Obilana AB, Ochanda J, Souissi T, Tzotzos G (2004) Major heretofore intractable biotic constraints to African food security that may be amenable to novel biotechnological solutions. Crop Prot 23:661-689

Guan JC, Koch KE, Suzuki M, Wu S, Latshaw S, Petruff T, Goulet C, Klee HJ, McCarty DR (2012) Diverse roles of strigolactone signaling in maize architecture and the uncoupling of a branching-specific subnetwork. Plant Physiol 160:1303-1317

Gutjahr C (2014) Phytohormone signaling in arbuscular mycorhiza development. Curr Opin Plant Biol 20:26-34

Gutjahr C, Parniske M (2013) Cell and developmental biology of arbuscular mycorrhiza symbiosis. Annu Rev Cell Dev Biol 29:593-617 
Ha CV, Leyva-Gonzalez MA, Osakabe Y, Tran UT, Nishiyama R, Watanabe Y, Tanaka M, Seki M, Yamaguchi S, Dong NV, Yamaguchi-Shinozaki K, Shinozaki K, Herrera-Estrella L, Tran LSP (2014) Positive regulatory role of strigolactone in plant responses to drought and salt stress. Proc Natl Acad Sci U S A 111:851-856

Hagerberg D, Manique N, Brandt KK, Larsen J, Nybroe O, Olsson S (2011) Low concentration of copper inhibits colonization of soil by the arbuscular mycorrhizal fungus Glomus intraradices and changes the microbial community structure. Microb Ecol 61:844-852

Hamiaux C, Drummond RSM, Janssen BJ, Ledger SE, Cooney JM, Newcomb RD, Snowden KC (2012) DAD2 is an $\alpha / \beta$ hydrolase likely to be involved in the perception of the plant branching hormone strigolactone. Curr Biol 22:2032-2036

Harrison MJ (2005) Signaling in the arbuscular mycorrhizal symbiosis. Annu Rev Microbiol 59:19-42

Hassan S, Mathesius U (2012) The role of flavonoids in rootrhizosphere signalling: opportunities and challenges for improving plant-microbe interactions. J Exp Bot 63:34293444

Herrera-Medina MJ, Steinkellner S, Vierheilig H, Bote JAO, Garrido JMG (2007) Abscisic acid determines arbuscule development and functionality in the tomato arbuscular mycorrhiza. New Phytol 175:554-564

Hetrick BAD, Bockus WW, Bloom J (1984) The role of vesicular arbuscular mycorrhizal fungi in the growth of Kansas winterwheat. Can J Bot 62:735-740

Hong JH, Seah SW, Xu J (2013) The root of ABA action in environmental stress response. Plant Cell Rep 32:971-983

Hu Y, Wu S, Sun Y, Li T, Zhang X, Chen C, Lin G, Chen B (2015) Arbuscular mycorrhizal symbiosis can mitigate the negative effects of night warming on physiological traits of Medicago truncatula L. Mycorrhiza 25:131-42

Jamil M, Charnikhova T, Cardoso C, Jamil T, Ueno K, Verstappen F, Asami T, Bouwmeester HJ (2011a) Quantification of the relationship between strigolactones and Striga hermonthica infection in rice under varying levels of nitrogen and phosphorus. Weed Res 51:373-385

Jamil M, Rodenburg J, Charnikhova T, Bouwmeester HJ (2011b) Pre-attachment Striga hermonthica resistance of New Rice for Africa (NERICA) cultivars based on low strigolactone production. New Phytol 192:964-975

Jiang L, Liu X, Xiong G, Liu H, Chen F, Wang L, Meng X, Liu G, Yu H, Yuan Y, Yi W, Zhao L, Ma H, He Y, Wu Z, Melcher K, Qian Q, Xu HE, Wang Y, Li J (2013) DWARF 53 acts as a repressor of strigolactone signalling in rice. Nature 504:401405

Joel DM, Hershenhom Y, Eizenberg H, Aly R, Ejeta G, Rich JP, Ransom JK, Sauerborn J, Rubiales D (2007) Biology and management of weedy root parasites. Hortic Rev 33: 267-349

Kapulnik Y, Delaux PM, Resnick N, Mayzlish-Gati E, Wininger S, Bhattacharya C, Sejalon-Delmas N, Combier JP, Becard G, Belausov E, Beeckman T, Dor E, Hershenhorn J, Koltai H (2011a) Strigolactones affect lateral root formation and roothair elongation in Arabidopsis. Planta 233:209-216

Kapulnik Y, Resnick N, Mayzlish-Gati E, Kaplan Y, Wininger S, Hershenhorn J, Koltai H (2011b) Strigolactones interact with ethylene and auxin in regulating root-hair elongation in Arabidopsis. J Exp Bot 62:2915-2924
Kelly CN, Morton JB, Cumming JR (2005) Variation in aluminum resistance among arbuscular mycorrhizal fungi. Mycorrhiza 15:193-201

Kohlen W, Charnikhova T, Liu Q, Bours R, Domagalska MA, Beguerie S, Verstappen F, Leyser O, Bouwmeester H, Ruyter-Spira C (2011) Strigolactones are transported through the xylem and play a key role in shoot architectural response to phosphate deficiency in nonarbuscular mycorrhizal host Arabidopsis. Plant Physiol 155:974-987

Kohlen W, Charnikhova T, Lammers M, Pollina T, Toth P, Haider I, Pozo MJ, de Maagd RA, Ruyter-Spira C, Bouwmeester HJ, López-Ráez JA (2012) The tomato CAROTENOID CLEA VAGE DIOXYGENASE8 (SlCCD8) regulates rhizosphere signaling, plant architecture and affects reproductive development through strigolactone biosynthesis. New Phytol 196: $535-547$

Koltai H (2011) Strigolactones are regulators of root development. New Phytol 190:545-549

Koltai H, Dor E, Hershenhorn J, Joel DM, Weininger S, Lekalla S, Shealtiel H, Bhattacharya C, Eliahu E, Resnick N, Barg R, Kapulnik Y (2010) Strigolactones' effect on root growth and root-hair elongation may be mediated by auxin-efflux carriers. J Plant Growth Regul 29:129-136

Ledger SE, Janssen BJ, Karunairetnam S, Wang T, Snowden KC (2010) Modified CAROTENOID CLEAVAGE DIOXYGENASE8 expression correlates with altered branching in kiwifruit (Actinidia chinensis). New Phytol 188:803-813

Lendzemo VW, Kuyper TW, Kropff MJ, van Ast A (2005) Field inoculation with arbuscular mycorrhizal fungi reduces Striga hermonthica performance on cereal crops and has the potential to contribute to integrated Striga management. Field Crop Res 91:51-61

Li H, Smith FA, Dickson S, Holloway RE, Smith SE (2008) Plant growth depressions in arbuscular mycorrhizal symbioses: not just caused by carbon drain? New Phytol 178:852-62

Li Z, Xu C, Li K, Yan S, Qu X, Zhang J (2012) Phosphate starvation of maize inhibits lateral root formation and alters gene expression in the lateral root primordium zone. BMC Plant Biol 12:89

Li T, Lin G, Zhang X, Chen Y, Zhang S, Chen B (2014) Relative importance of an arbuscular mycorrhizal fungus (Rhizophagus intraradices) and root hairs in plant drought tolerance. Mycorrhiza 24:595-602

Liu ZL, Li YJ, Hou HY, Zhu XC, Rai V, He XY, Tian CJ (2013) Differences in the arbuscular mycorrhizal fungi-improved rice resistance to low temperature at two $\mathrm{N}$ levels: aspects of $\mathrm{N}$ and $\mathrm{C}$ metabolism on the plant side. Plant Physiol Biochem 71:87-95

Liu J, He H, Vitali M, Visentin I, Charnikhova T, Haider I, Schubert A, Ruyter-Spira C, Bouwmeester HJ, Lovisolo C, Cardinale F (2015) Osmotic stress represses strigolactone biosynthesis in Lotus japonicus roots: exploring the interaction between strigolactones and ABA under abiotic stress. Planta 241:1435-1451

López-Ráez JA, Charnikhova T, Gómez-Roldán V, Matusova R, Kohlen W, De Vos R, Verstappen F, Puech-Pages V, Bécard G, Mulder P, Bouwmeester H (2008a) Tomato strigolactones are derived from carotenoids and their biosynthesis is promoted by phosphate starvation. New Phytol 178:863-874 
López-Ráez JA, Charnikhova T, Mulder P, Kohlen W, Bino R, Levin I, Bouwmeester H (2008b) Susceptibility of the tomato mutant high pigment- $2^{d g}\left(\mathrm{hp}-2^{d g}\right)$ to Orobanche spp infection. J Agric Food Chem 56:6326-6332

López-Ráez JA, Matusova R, Cardoso C, Jamil M, Charnikhova T, Kohlen W, Ruyter-Spira C, Verstappen F, Bouwmeester H (2009) Strigolactones: ecological significance and use as a target for parasitic plant control. Pest Manag Sci 64:471-477

López-Ráez JA, Kohlen W, Charnikhova T, Mulder P, Undas AK, Sergeant MJ, Verstappen F, Bugg TDH, Thompson AJ, Ruyter-Spira C, Bouwmeester H (2010b) Does abscisic acid affect strigolactone biosynthesis? New Phytol 187:343-354

López-Ráez JA, Charnikhova T, Fernández I, Bouwmeester H, Pozo MJ (2011a) Arbuscular mycorrhizal symbiosis decreases strigolactone production in tomato. J Plant Physiol 168:294-297

López-Ráez JA, Pozo MJ, García-Garrido JM (2011b) Strigolactones: a cry for help in the rhizosphere. Botany 89:513-522

López-Ráez JA, Fernández I, García JM, Berrio E, Bonfante P, Walter MH, Pozo MJ (2015) Differential spatio-temporal expression of carotenoid cleavage dioxygenases regulates apocarotenoid fluxes during AM symbiosis. Plant Sci 230: 59-69

Maillet F, Poinsot V, Andre O, Puech-Pages V, Haouy A, Gueunier M, Cromer L, Giraudet D, Formey D, Niebel A, Martinez EA, Driguez H, Becard G, Denarie J (2011) Fungal lipochitooligosaccharide symbiotic signals in arbuscular mycorrhiza. Nature 469:58-63

Martín-Rodríguez JA, Leon-Morcillo R, Vierheilig H, Ocampo JA, Ludwig-Muller J, García-Garrido JM (2011) Ethylenedependent/ethylene-independent ABA regulation of tomato plants colonized by arbuscular mycorrhiza fungi. New Phytol 190:193-205

Matusova R, Rani K, Verstappen FWA, Franssen MCR, Beale $\mathrm{MH}$, Bouwmeester HJ (2005) The strigolactone germination stimulants of the plant-parasitic Striga and Orobanche spp are derived from the carotenoid pathway. Plant Physiol 139: 920-934

Mayzlish-Gati E, De-Cuyper C, Goormachtig S, Beeckman T, Vuylsteke M, Brewer PB, Beveridge CA, Yermiyahu U, Kaplan Y, Enzer Y, Wininger S, Resnick N, Cohen M, Kapulnik Y, Koltai H (2012) Strigolactones are involved in root response to low phosphate conditions in Arabidopsis. Plant Physiol 160:1329-1341

Murray JD (2011) Invasion by invitation: rhizobial infection in legumes. Mol Plant-Microbe Interact 24:631-639

Niu YF, Chai RS, Jin GL, Wang H, Tang CX, Zhang YS (2013) Responses of root architecture development to low phosphorus availability: a review. Ann Bot 112:391-408

Nouri E, Breuillin-Sessoms F, Feller U, Reinhardt D (2014) Phosphorus and nitrogen regulate arbuscular mycorrhizal symbiosis in petunia hybrida. PLoS One 9(6):e90841

Ohmiya A (2009) Carotenoid cleavage dioxygenases and their apocarotenoid products in plants. Plant Biotech 26:351-358

Oldroyd GED, Downie JA (2008) Coordinating nodule morphogenesis with rhizobial infection in legumes. Annu Rev Plant Biol 59:519-546

Omirou M, Ioannides IM, Ehaliotis C (2013) Mycorrhizal inoculation affects arbuscular mycorrhizal diversity in watermelon roots, but leadstoimproved colonizationand plant response under water stress only. Appl Soil Ecol 63:112-119
Pandya-Kumar N, Shema R, Kumar R, Mayzlish-Gati E, Levy D, Zemach H, Belausov E, Winingen S, Abu-Abied M, Kapulnik Y, Koltai H (2014) Strigolactone analog GR24 triggers changes in PIN2 polarity, vesicle trafficking and actin filament architecture. New Phytol 202:1184-1196

Parker C (2009) Observations on the current status of Orobanche and Striga problems worldwide. Pest Manag Sci 65:453-459

Péret B, Clément M, Nussaume L, Desnos T (2011) Root developmental adaptation to phosphate starvation: better safe than sorry. Trends Plant Sci 16:442-450

Pozo MJ, López-Ráez JA, García-Garrido JM (2015) Phytohormones as integrators of environmental signals in the regulation of mycorrhizal symbioses. New Phytol 205: $1431-1436$

Rasmussen A, Mason MG, De Cuyper C, Brewer PB, Herold S, Agusti J, Geelen D, Greb T, Goormachtig S, Beeckman T, Beveridge CA (2012) Strigolactones suppress adventitious rooting in Arabidopsis and pea. Plant Physiol 158:19761987

Reinhardt D (2007) Programming good relations - development of the arbuscular mycorrhizal symbiosis. Curr Opin Plant Biol 10:98-105

Rispail N, Dita MA, Gonzalez-Verdejo C, Perez-de-Luque A, Castillejo MA, Prats E, Roman B, Jorrin J, Rubiales D (2007) Plant resistance to parasitic plants: molecular approaches to an old foe. New Phytol 173:703-711

Rouached H, Arpat AB, Poirier Y (2010) Regulation of phosphate starvation responses in plants: signaling players and crosstalks. Mol Plant 3:288-299

Ruiz-Lozano JM, Porcel R, Azcón C, Aroca R (2012) Regulation by arbuscular mycorrhizae of the integrated physiological response to salinity in plants: new challenges in physiological and molecular studies. J Exp Bot 63: 4033-4044

Ruyter-Spira C, Kohlen W, Charnikhova T, van Zeijl A, van Bezouwen L, de Ruijter N, Cardoso C, López-Ráez JA, Matusova R, Bours R, Verstappen F, Bouwmeester H (2011) Physiological effects of the synthetic strigolactone analog GR24 on root system architecture in Arabidopsis: another belowground role for strigolactones? Plant Physiol 155:721-734

Ruyter-Spira C, Al-Babili S, van der Krol S, Bouwmeester H (2013) The biology of strigolactones. Trends Plant Sci 18: $72-83$

Satish K, Gutema Z, Grenier C, Rich PJ, Ejeta G (2012) Molecular tagging and validation of microsatellite markers linked to the low germination stimulant gene (lgs) for Striga resistance in sorghum [Sorghum bicolor (L.) Moench]. Theor Appl Genet 124:989-1003

Schachtman DP, Reid RJ, Ayling SM (1998) Phosphorus uptake by plants: from soil to cell. Plant Physiol 116:447-453

Scholes JD, Press MC (2008) Striga infestation of cereal crops - an unsolved problem in resource limited agriculture. Curr Opin Plant Biol 11:180-186

Seto Y, Sado A, Asami K, Hanada A, Umehara M, Akiyama K, Yamaguchi S (2014) Carlactone is an endogenous biosynthetic precursor for strigolactones. Proc Natl Acad Sci U S A 111:1640-1645

Shahabivand S, Maivan HZ, Goltapeh EM, Sharifi M, Aliloo AA (2012) The effects of root endophyte and arbuscular 
mycorrhizal fungi on growth and cadmium accumulation in wheat under cadmium toxicity. Plant Physiol Biochem 60: 53-58

Shinohara N, Taylor C, Leyser O (2013) Strigolactone can promote or inhibit shoot branching by triggering rapid depletion of the auxin efflux protein PIN1 from the plasma membrane. PLoS Biol 11, e1001474

Singh LP, Gill SS, Tuteja N (2011) Unraveling the role of fungal symbionts in plant abiotic stress tolerance. Plant Signal Behav 6:175-191

Smith SE, Read DJ (2008) Mycorrhizal Symbiosis, Ed 3. Academic Press, New York

Smith SE, Smith FA (2011) Roles of arbuscular mycorrhizas in plant nutrition and growth: new paradigms from cellular to ecosystem scales. Annu Rev Plant Biol 62:227-250

Smith SE, Smith FA (2012) Fresh perspectives on the roles of arbuscular mycorrhizal fungi in plant nutrition and growty. Mycologia 104:1-13

Smith SE, Facelli E, Pope S, Smith FA (2010) Plant performance in stressful environments: interpreting new and established knowledge of the roles of arbuscular mycorrhizas. Plant Soil 326:3-20

Soto MJ, Fernandez-Aparicio M, Castellanos-Morales V, GarciaGarrido JM, Ocampo JA, Delgado MJ, Vierheilig H (2010) First indications for the involvement of strigolactones on nodule formation in alfalfa (Medicago sativa). Soil Biol Biochem 42:383-385

Staehelin C, Xie ZP, Illana A, Vierheilig H (2011) Long-distance transport of signals during symbiosis: are nodule formation and mycorrhization autoregulated in a similar way? Plant Signal Behav 6:372-377

Steinkellner S, Lendzemo V, Langer I, Schweiger P, Khaosaad T, Toussaint JP, Vierheilig H (2007) Flavonoids and strigolactones in root exudates as signals in symbiotic and pathogenic plant-fungus interactions. Molecules 12:12901306

Stepanova AN, Alonso JM (2009) Ethylene signaling and response: where different regulatory modules meet. Curr Opin Plant Biol 12:548-555

Sun H, Tao J, Liu S, Huang S, Cheng S, Xie X, Yoneyama $\mathrm{K}$, Zhang Y, Xu G (2014) Strigolactones are involved in phosphate- and nitrate-deficiency-induced root development and auxin transport in rice. J Exp Bot 6: 6735-6746

Sunil Kumar CP, Garampalli RH (2013) Diversity of arbuscular mycorrhizal fungi in irrigated and non-irrigated fields of southern Karnataka, India. J Environ Biol 34:159-164

Torres-Vera R, García JM, Pozo MJ, López-Ráez JA (2014) Do strigolactones contribute to plant defence? Mol Plant Pathol $15: 211-216$

Uehlein N, Fileschi K, Eckert M, Bienert GP, Bertl A, Kaldenhoff R (2007) Arbuscular mycorrhizal symbiosis and plant aquaporin expression. Phytochemistry 68:122-129

Umehara M, Hanada A, Yoshida S, Akiyama K, Arite T, TakedaKamiya N, Magome H, Kamiya Y, Shirasu K, Yoneyama K, Kyozuka J, Yamaguchi S (2008) Inhibition of shoot branching by new terpenoid plant hormones. Nature 455:195-200

Umehara M, Hanada A, Magome H, Takeda-Kamiya N, Yamaguchi S (2010) Contribution of strigolactones to the inhibition of tiller bud outgrowth under phosphate deficiency in rice. Plant Cell Physiol 51:1118-1126 van der Heijden MGA, Bardgett RD, van Straalen NM (2008) The unseen majority: soil microbes as drivers of plant diversity and productivity in terrestrial ecosystems. Ecol Lett 11:296310

Vogel JT, Walter MH, Giavalisco P, Lytovchenko A, Kohlen W, Charnikhova T, Simkin AJ, Goulet C, Strack D, Bouwmeester HJ, Fernie AR, Klee HJ (2010) SlCCD7 controls strigolactone biosynthesis, shoot branching and mycorrhiza-induced apocarotenoid formation in tomato. Plant J 61:300-311

Walter MH (2013) Role of carotenoid metabolism in the arbuscular mycorrhizal symbiosis. In Molecular Microbial Ecology of the Rhizospherede (ed Bruijn FJ). WileyBlackwell, pp 513-524

Walter MH, Strack D (2011) Carotenoids and their cleavage products: biosynthesis and functions. Nat Prod Rep 28: 663-692

Wang Y, Sun S, Zhu W, Jia K, Yang H, Wang X (2013) Strigolactone/MAX2-induced degradation of brassinosteroid transcriptional effector BES1 regulates shoot branching. Dev Cell 27:681-688

Wu QS, Xia RX (2006) Arbuscular mycorrhizal fungi influence growth, osmotic adjustment and photosynthesis of citrus under well-watered and water stress conditions. J Plant Physiol 163:417-425

Xie XN, Yoneyama K, Yoneyama K (2010) The strigolactone story. Annu Rev Phytopathol 48:93-117

Xie XN, Yoneyama K, Kisugi T, Uchida K, Ito S, Akiyama K, Hayashi H, Yokota T, Nomura T, Yoneyama K (2013) Confirming stereochemical structures of strigolactones produced by rice and tobacco. Mol Plant 6:153-163

Yamada Y, Furusawa S, Nagasaka S, Shimomura K, Yamaguchi S, Umehara M (2014) Strigolactone signaling regulates rice leaf senescence in response to a phosphate deficiency. Planta 240: 399-408

Yoder JI, Scholes JD (2010) Host plant resistance to parasitic weeds; recent progress and bottlenecks. Curr Opin Plant Biol 13:478-484

Yoneyama K, Xie X, Kisugi T, Nomura T, Yoneyama K (2013) Nitrogen and phosphorus fertilization negatively affects strigolactone production and exudation in sorghum. Planta 238:885-894

Yoneyama K, Xie X, Kusumoto D, Sekimoto H, Sugimoto Y, Takeuchi Y, Yoneyama K (2007) Nitrogen deficiency as well as phosphorous deficiency in sorghum promotes the production and exudation of 5-deoxystrigol, the host recognition signal for arbuscular mycorrhizal fungi and root parasites. Planta 227:125-132

Yoneyama K, Xie X, Yoneyama K, Takeuchi Y (2009) Strigolactones: structures and biological activities. Pest Manag Sci 65:467-470

Yoneyama K, Xie X, Kim HI, Kisugi T, Nomura T, Sekimoto H, Yokota T, Yoneyama K (2012) How do nitrogen and phosphorus deficiencies affect strigolactone production and exudation? Planta 235:1197-1207

Zhang Y, van Dijk DJA, Scaffidi A, Flematti GR, Hofmann M, Charnikhova T, Verstappen F, Hepworth J, van der Krol S, Leyser O, Smith SM, Zwanenburg B, Al-Babili S, RuyterSpira C, Bouwmeester HJ (2014) Rice cytochrome P450 MAX1 homologs catalyze distinct steps in strigolactone biosynthesis. Nat Chem Biol 10:1028-1033 
Zhou F, Lin Q, Zhu L, Ren Y, Zhou K, Shabek N, Wu F, Mao H, Dong W, Gan L, Ma W, Gao H, Chen J, Yang C, Wang D, Tan J, Zhang X, Guo X, Wang J, Jiang L, Liu X, Chen W, Chu J, Yan C, Ueno K, Ito S, Asami T, Cheng Z, Lei C, Zhai H, Wu C, Wang H, Zheng N, Wan J (2013) D14-SCF D3dependent degradation of D53 regulates strigolactone signalling. Nature 504:406-410
Zhu XC, Song FB, Liu SQ, Liu TD, Zhou X (2012) Arbuscular mycorrhizae improves photosynthesis and water status of Zea mays L. under drought stress. Plant Soil Environ 58: 186-19

Zwanenburg B, Pospíšil T (2013) Structure and activity of strigolactones: new plant hormones with a rich future. Mol Plant 6:38-62 